\title{
Functional Analysis of Neonatal Intensive Care Centers and Effective Operation Plan
}

\author{
Eun Sun Kim, M.D., Ph.D., Seung Han Shin, M.D.*, and Han-Suk Kim, M.D., Ph.D.* \\ Department of Pediatrics, CHA Gangnam Medical Center, CHA University School of Medicine, Seoul, Korea \\ Division of Neonatology, Department of Pediatrics*, Seoul National University College of Medicine, Seoul, Korea
}

\section{ABSTRACT}

Regional hub neonatal intensive care centers are opening supported by Ministry of Health and Welfare, with the need for more neonatal intensive care unit (NICU) beds response to increasing number of prematurity. Besides beds expansion, functional role of NICU is important and the evaluation tool of functional analysis of NICU is necessary. In this review, admission of preterm infant born before 32 gestational weeks was considered as a functional component and the annual number of those babies was used as an activity marker. The activity of NICU was higher with increased bed number, but also increased equipment, NICU personnel, obstetric personnel were independent factors for the higher NICU activity. Levels of NICU can be defined according to the activity, and reference bed size, equipment, personnel can be defined according to each level. In reverse, functional analysis of NICU can be performed with known bed size or equipment predicting activity level. Meanwhile, the evaluation of 13 regional hub NICU revealed that they partially contributed to the regionalization of NICU, and the activity was increased in all regional hub NICUs. Three regional hub NICUs showed markedly increased activity after opening, and those centers showed increased NICU personnel and obstetric personnel compared to other centers. In terms of regional hub government support, multilateral plan should be operated, besides simple bed size, considering distribution of different functional level of regional NICUs and leaking patient in the region.

Key Words: Neonatal intensive care unit level, Preterm infant, Patient volume, Regionalization

\section{서론}

총 출산율이 줄었음에도 불구하고 미숙아 및 저체중출생아 출산율 증가에 따라 신생아중 환자실의 필요성이 증대되고 있다. 2012년 통계청 자료에 따르면 1993년 총 출생아 715,826 명
Received: 27 May 2012

Revised: 30 May 2013

Accepted: 31 May 2013

Correspondence to:

Han-Suk Kim, M.D., Ph.D.

Department of Pediatrics, Seoul

National University College of

Medicine, 103 Daehak-ro, Jongno-

gu, Seoul 110-799, Korea

Tel: +82-2-2072-1696,

Fax: +82-2-743-3455,

E-mail: kimhans@snu.ac.kr

Copyright(c)

By Korean Society of Neonatology.

All right reserved. 
중 출생체중 $2,500 \mathrm{~g}$ 이하의 저체중출생아의 수가 18,532 명으로 $2.6 \%$ 였던 데에 비하여 2002 년 총 출생아 492,111 명 중 24,048 명으 로 $3.8 \%$ 로 증가하였고, 2011 년 총 출생아 471,265 명 중 24,647 명 으로 $5.2 \%$ 까지 증가하였다 ${ }^{1}$. 출생체중 $1,500 \mathrm{~g}$ 이하의 극소저체중 출생아는 1993년도 929 명인 것에 비하여 2011년도에는 2,994 명으 로 수적으로는 $322 \%$ 로 증가하였고, 전체 총 출생아에서 차지하는 비율 또한 $0.13 \%$ 에서 $0.64 \%$ 로 $492 \%$ 의 비율증가를 보여 ${ }^{1)}$ 향후 국 내의 저체중출생아 및 미숙아의 상대적 절대적 증가가 분명하다. 이러한 추이를 보았을 때 신생아집중치료를 필요로 하는 저체중 출생아 및 미숙아의 비율 증가 및 절대수 증가에 대한 국가적 대처 계획 수립이 시급한 문제이다.

1999년, 2006년, 2010년 대한신생아학회에서 보건복지부의 지 원을 받아 전국 신생아중환자실 규모를 조사한 바 있고, 이를 통 해 국내 신생아중환자실에 필요한 병상 수를 산정하여 국가적 차 원에서 병상 수를 늘리기 위한 지원이 필요함을 제안하였다 ${ }^{2-4)}$. 이에 따라, 2008년부터 보건복지부에서 신생아 집중치료 지역센 터 지원이 시작되었고, 이 사업은 각 지방병원을 중심으로 2012 년 2 월까지 총 18 개 병원이 선정되어 사업이 진행되고 있다. 이 중 2011년까지 선정된 13 개소는 정부 지원 시작 후 각 10 병상이 더 확 보된 후에 지역센터라는 이름 하에 개소하여 진료 중에 있으며, 2012년에 지정된 센터들도 최근 속속들이 개소하고 있다. 이들은 정부 지원 하에 병상 수 확대, 장비, 설비, 인력 등의 보강 후 운영 비를 지원받으며 각 지방에서 기능하는 신생아 집중치료센터로 서의 역할을 기대 받고 있는 상태이다.

병상 수가 큰 신생아중환자실일수록 활발한 진료를 하겠지만 단순한 병상 수나 장비의 개수 등으로 해당 신생아중환자실이 얼 마나 기능을 하고 있는지를 평가하는 것에는 한계가 있다. 병상 수 확보의 일환으로 진행되고 있는 정부지원 신생아 집중치료센 터가 원만하게 진행되고 있는지를 평가하기 위해서는 신생아중 환자실의 기능 평가 도구가 필요하다. 정부지원 신생아 집중치료 센터 사업의 기능 평가를 통해 정부 지원의 효율성을 극대화 할 수 있을 것이다.

따라서, 본 종설에서는 보건복지부에 2012년 11월에 제출한 "신 생아집중치료센터의 기능과 효율적 운영에 관한 연구” 에서 ${ }^{5)}$ 조 사되었던 전국의 87개 신생아중환자실의 현황을 토대로 기능 현 황을 파악하기 위한 평가의 도구를 이용하여, 지역거점 신생아집 중치료센터 현황을 중간평가하며, 향후 정부지원의 방향에 대해 제안하고자 한다.

\section{본론}

\section{1. 신생아중환자실의 기능 평가}

신생아중환자실의 기능을 평가하기 위해, 규모의 지표인 병상 수 외에 복합적인 요소들을 평가할 수 있도록 활동성 지표의 사용 이 필요하다. 활동성은 신생아중환자실의 대표적인 환자인, 미숙 아 환자의 입원 양으로 정할 수 있다. 미국의 신생아집중치료기능 평가에서, 미숙아의 생존율은 신생아집중치료의 등급과 입원 수 에 비례하며, 환자양은 신생아중환자실의 등급에 따라 결정된다 고 보고한바 있으며 ${ }^{6}$, 영국의 신생아중환자실 평가에서 입원 환 자 수가 많은 병원은 더 아픈 환자를 치료하며 타과의뢰나간호 인 력 등의 조건들이 더 풍부한 상위등급의 병원임을 보고하였닥. 출생 체중이 아닌, 산전에 알 수 있는 좀 더 정확한 정보인 출생 재 태주수를 기준으로 활동성과 관련된 결과를 본 다면 산모를 치료 할 수 있는 주산기적인 측면이 활동성에 포함될 수 있으므로, 재 태주수 32 주 미만 출생아의 입원을 신생아중환자실의 기능 평가 요소로 사용하여, 연간 입원 환자 수를 활동성의 지표로 사용할 수 있다.

1) 출생 재태주수 32 주 미만의 입원 수: 활동성 지표

재태주수 32 주 미만의 미숙아들은 장기의 미숙으로 미숙아에 서 흔한 호흡곤란증후군, 기관지폐이형성이상, 동맥관 개존증, 뇌실내 출혈, 괴사성 장염, 미숙아 망막증 등의 질병 이환율이 급 격히 증가되어 질환의 이환율과 관련하여 신생아중환자실에서 특별한 치료를 필요로 하는 환자 군이다 ${ }^{8-15)}$.

연간 재태주수 32 주 미만의 미숙아 입원 수를 기준으로 한 신생 아중환자실의 활동성 지표는 중증질환 환자 수를 반영한다. 전국 의 87 개 신생아중환자실에서 2011 년 1 년간 호흡곤란증후군 진단 환자 수와 기관지폐이형성이상 진단 환자 수는 활동성 지표와 유 의한 상관관계를 보였다 $\left(\mathrm{r}^{2}=0.67, P=0.000 ; \mathrm{r}^{2}=0.87, P=0.000\right.$ by Pearson's correlation), 병상 당 활동성 지표와 병상 당 중증질환 환자 수의 관계를 보았을 때도 유의한 상관관계를 보였다 ${ }^{5}$ (병상 당 호흡곤란증후군 환자 수: $\mathrm{r}^{2}=0.57, P=0.000$; 병상 당 기관지폐 이형성이상 환자 수: $\left.\mathrm{r}^{2}=0.68, P=0.000\right)$.

연간 재태주수 32 주 미만의 미숙아 입원 수를 기준으로 한 신생 아중환자실의 활동성 지표는 신생아중환자관리의 질을 대표하는 극소재태주수 미숙아의 생존율을 반영한다. 2011년 1년간 전수조 사 된 87 개 신생아중환자실에서 각각 출생 주수 32 주 미만으로 입 원한 환자들의 수와 재태주수 28 주 미만의 생존율은 유의한 양의 상관관계를 보였다 ${ }^{5}\left(\mathrm{r}^{2}=0.355, P=0.001\right)$.

2) 국내 신생아중환자실의 현황: 활동성이 없는 병원 존재 2012년 10월에 건강보험심사평가원에 신고 된 국내 신생아중환 자실은 108 곳이나, 허수로 신고된 신생아중환자실 병상을 제외하 고 2012년 10월까지 조사된 바에 따르면 국내의 신생아중환자실 운영 병원은 89 곳이며, 총 병상 수는 1,299 개로 정부 지원 병상 수 확보의 사업으로 감소추세이던 신생아중환자실 병상 수가 최근 약간 증가되었다. 이 중에서도 실제로 신생아중환자실이 기능을 
하고 있다면, 신생아중환자 관리료를 받고 있는 입원 환자가 있어 야 하며 32주 미만 입원이 있어 활동성을 보여야 한다. 2011년 1년 간 건강보험심사평가원에 보고된 신생아중환자 관리료 청구 현 황과 전수 조사에 따르면 연간 신생아중환자 관리료가 0-1건 또 는 32주 미만 입원 수가 0-1건인 병원은 총 11곳이었다. 또한 전수 조사에서 누락된 2 개의 병원도 활동성이 없다고 전화설문 상 보 고하고 있다. 따라서, 국내 신생아중환자실 중 기능을 하고 있는 곳은 89 곳 중 13 곳을 제외한 76 곳으로 확인된다 ${ }^{5}$. 기능하고 있지 않은 신생아중환자실 병상 신고 병원 중 11곳은 3-7병상으로 작은 규모의 병상이며, 나머지 병원은 각각 10 병상, 20 병상의 병원이었 다. 전수 조사된 병상 7 개 미만의 20 개 신생아중환자실 중 활동성 이 없는 10 곳의 병원과 활동성을 보이는 10 곳의 병원을 비교하였 을 때(병상 수 $5 \pm 2$ vs. $6 \pm 1, P=0.308$ by Mann-Whitney test), 활 동성이 없는 병원은 인큐베이터 수( $6 \pm 2$ vs. $11 \pm 5, P=0.009)$, 환 자모니터 수( $5 \pm 3$ vs. $11 \pm 6, P=0.033$ ) 등 시설 - 장비가 유의하게 적었고, 근무 전공의 $(0.8 \pm 0.6$ vs. $1.5 \pm 1.1, P=0.094)$ 와 세부 전문 의( $0.6 \pm 0.5 \mathrm{vs} .1 .0 \pm 0.5, P=0.087)$ 등 인력이 적었고, 분만가능 산과 전문의 당 32 주 미만 조산아 분만 건수가 유의하게 적었다 ${ }^{5}$ (0.7 \pm 1.7 vs. $7.3 \pm 5.1, P=0.003)$.

3) 국내 신생아중환자실의 현황: 활동성에 따른 분류

연간 재태주수 32 주 미만의 미숙아 입원 수를 기준으로 한 신 생아중환자실의 활동성 지표에 영향을 주는 요인을 살펴보기 위 해 병상 수, 크기, 시설, 장비, 신생아중환자실 인력, 산과 인력을 요인으로 하여 전수조사 된 87개 병원의 활동성 지표를 살펴보았 다. 상기 요인들은 활동성이 올라갈수록 증가되어 있는 양상을 보 였다. 전수조사 된 87개 병원의 활동성을 사분할하여 하위 두번 째 분할(50백분위수) 기준인 35 명 미만의 입원환자가 있는 병원을 level 1 (하위 등급), 연간 35 명 이상 55 명 이하로( 75 백분위수) 입원 하는 병원을 level 2 (중위 등급), 연간 55 명 초과의 입원환자가 있 는 병원을 level 3 (상위 등급)으로 분류하였고, 상위 등급의 병원 중에서도 상위 10 percentile (90백분위수)에 속하는 병원을 level $3+$ (최상위 등급)으로 따로 나누었다. 이러한 분류는 영국에서 1 년간 입원하는 극소저체중출생아의 수에 따라 high-volume 그룹 을 연간 57명 초과, medium-volume 그룹을 연간 35-57명, lowvolume 그룹을 연간 35 명 미만으로 분류하여 신생아중환자실의 기능을 분석하였던 것과 유사한 분류이닥.

신생아중환자실의 등급에 따라 병상 수, 장비, 인력, 타과 협 진, 산과 인력 등의 요인들이 통계적으로 유의한 차이를 보였다 (Table 1). 등급에 따른 병상 수의 차이가 가장 뚜렷하였지만, 병 상 수 외에 활동성에 영향을 주는 변수들에 대한 분석을 시행하 기 위해 단변수 분석에서 유의한 변수들 중 크기, 장비, 인력을 대표할 수 있는 병상 수(포아송 회귀분석을 수행한 단변수 분석 $P<0.0001)$, 인공호흡기 수 $(P<0.0001)$, 근무 전문의 수 $(P<0.0001)$,
신생아중환자실 간호사 수 $(P<0.0001)$, 분만가능 산과 전문의 수 $(P=0.0007)$, 총 5 개의 변수로 다변수 분석을 시행하였다. 포아 송 회귀분석을 통한 다변수 분석 시, 추정 적합식은, $\log$ [전체 32 주 미만 입원 수 $=2.9298+0.0319 *$ (병상 수) $+0.0123 *$ (총 인공 호흡기 수) $+0.0468 *$ (근무 소아과 전문의 수) $+0.0149 *$ (간호사 수) $+0.0083 *$ (분만 가능 산과 전문의 수)로, 다른 변수들이 보정되 었을 때 상기 변수들이 독립적으로 활동성을 올리는 지표임을 보 여준다 $)^{5}$.

4) 국내 신생아중환자실의 등급화를 활용한 기능 평가 가능

출생 재태주수 32 주 미만 입원 환자 수를 이용한 활동성 분류를 통해 신생아중환자실을 등급화하였을 때, 병상 규모가 가장 큰 영 향 요인이었고, 각 등급별 평균 병상 수를 기준으로 규모 별 등급 에 맞는 시설 · 장비 · 인력을 권장할 수 있고, 규모 별 등급에 맞는 활동성을 예측할 수 있다. 예를 들어, 15 병상 이상의 신생아중환 자실은 level 2 에 맞추었을 때, 인공호흡기 수는 7 개 이상, 인큐베 이터 수는 15 개 이상, 전문의 수는 2 명 권장가능하고 세부전문의 수는 1 명 이상 필수로 존재해야 하는 것을 기준화 할 수 있다. 또한 이러한 규모와 시설 - 장비 · 인력에서 32 주 미만 입원아가 연간 50 명 정도로 활동성이 예측된다. Level 2 는 15 병상, level 3 는 25 병상, level $3+$ 는 35 병상 기준으로 분류하여 여기에 맞는 시설 · 장비 · 인 력 기준을 확인하고, 활동성을 평가한다면 신생아중환자실의 기 능 평가 도구로 사용할 수 있을 것이다.

\section{2. 지역거점 신생아집중치료센터의 기능 평가}

2008년부터 2012년까지 총 18개소에 지역거점 신생아집중치료 센터가 지정되어 약 1 년의 개소 준비 기간을 거쳐 2011년까지 지정 된 13 개 센터가 개소하였다(편의상 A-M 센터로 구분, 2012년 3월 까지 개소). 본 종설에서는 센터 지정 전 - 후의 활동성 변화를 평 가하기 위해 개소 후 6 개월 이상의 자료를 확보할 수 있었던 13 개 센터의 자료를 이용하여 분석하였다).

1) 지역화에 기여

지역거점 신생아집중치료센터는 2008년부터 2011년까지 부산, 대구, 인천, 광주, 대전, 강원도, 충청북도, 충청남도, 전라북도, 경상남도, 제주도에 각각 1 곳씩, 경기도에 2 곳이 지정되어 개소되 었다. 각 지역별 신생아중환자실의 출생 재태주수 32 주 미만의 입 원 환자수를 활성도 지표로 하여, 각 지역에서 출생한 해당 미숙 아들이 각 지역 내에서 $100 \%$ 흡수가 가능하다면 지역거점 센터로 서의 역할을 하고 있다고 볼 수 있다. 2011년 1년간 출생한 32주 미 만 미숙아의 통계청 자료를 통해 보았을 때 인천, 울산, 경기도, 충 청도, 전라도, 경상도에서는 아직 지역 신생아중환자실에서 지역 환자를 100\% 흡수하지는 못하고 있다(Table 2). 그러나, 2009년 1 년간 출생한 32 주 미만 미숙아 자료와 비교 시 강원도, 제주 지역 은 $100 \%$ 지역흡수율을 달성하였고, 인천지역은 흡수율 증가와 절 
Table 1. NICU Levels Classified by the Activity Defined as Annual Volume of Preterm Infant Born Before $<32$ Gestational Week

\begin{tabular}{|c|c|c|c|c|c|}
\hline & $\begin{array}{c}\text { Total } \\
(\mathrm{n}=87)\end{array}$ & $\begin{array}{l}\text { Level } 1 \\
(\mathrm{n}=42)\end{array}$ & $\begin{array}{l}\text { Level } 2 \\
(\mathrm{n}=24)\end{array}$ & $\begin{array}{l}\text { Level 3 } \\
(\mathrm{n}=21)\end{array}$ & $\begin{array}{l}\text { Level 3+ } \\
\qquad(\mathrm{n}=9)\end{array}$ \\
\hline Infants born before GA 32 weeks (No.) & $\begin{array}{r}42.7 \pm 36.0 \\
(0-194)\end{array}$ & $\begin{array}{c}17.6 \pm 11.9^{*} \\
(0-34)\end{array}$ & $\begin{array}{c}44.8 \pm 6.2^{\|} \\
(35-55)\end{array}$ & $\begin{array}{c}90.4 \pm 39.1^{\dagger} \\
(57-194)\end{array}$ & $\begin{array}{c}123.1 \pm 40.9^{\ddagger} \\
(76-194)\end{array}$ \\
\hline NICU beds (No.) & $\begin{array}{r}14.5 \pm 9.2 \\
(3-50)\end{array}$ & $9.1 \pm 3.9^{*}$ & $14.9 \pm 6.4^{\|}$ & $25.1 \pm 10.4^{\dagger}$ & $30.8 \pm 10.8$ \\
\hline Total invasive ventilator (No.) & $7.4 \pm 4.8$ & $4.9 \pm 1.9$ & $7.1 \pm 2.3^{\|}$ & $12.8 \pm 6.5^{\dagger}$ & $17.0 \pm 7.4^{\ddagger}$ \\
\hline HFOV (No.) & $2.5 \pm 2.9$ & $1.4 \pm 1.2$ & $2.2 \pm 1.5$ & $4.9 \pm 4.6$ & $6.8 \pm 6.2$ \\
\hline Incubator (No.) & $16.1 \pm 8.4$ & $11.5 \pm 4.8^{*}$ & $15.8 \pm 5.4^{\|}$ & $25.7 \pm 8.9^{\dagger}$ & $31.9 \pm 6.1^{\ddagger}$ \\
\hline Patient monitor (No.) & $16.4 \pm 11.8$ & $9.2 \pm 4.1^{*}$ & $17.3 \pm 6.3^{\|}$ & $29.8 \pm 14.8^{\dagger}$ & $40.6 \pm 14.9^{\ddagger}$ \\
\hline Bed side gas analysis & $68(78 \%)$ & $29(69 \%)$ & $19(79 \%)$ & $20(95 \%)$ & $8(89 \%)$ \\
\hline Micro-sampling & $68(78 \%)$ & $28(67 \%)$ & $21(87 \%)$ & $19(90 \%)$ & $8(89 \%)$ \\
\hline Ultrasound in NICU & $57(66 \%)$ & $25(60 \%)$ & $16(67 \%)$ & $16(76 \%)^{\dagger}$ & $9(100 \%)$ \\
\hline iNO gas & $38(44 \%)$ & $11(26 \%)$ & $9(37 \%)^{\|}$ & $18(86 \%)^{\dagger}$ & $7(78 \%)$ \\
\hline Dialysis & $54(62 \%)$ & $19(45 \%)$ & $16(67 \%)$ & $19(90 \%)^{\dagger}$ & $8(89 \%)$ \\
\hline Hypothermia therapy & $26(30 \%)$ & $12(29 \%)$ & $2(8 \%)^{\|}$ & $12(57 \%)^{\dagger}$ & $7(78 \%)$ \\
\hline TPN for preemie & $76(87 \%)$ & $35(83 \%)$ & $21(87 \%)$ & $20(95 \%)$ & $9(100 \%)$ \\
\hline Bed side sonography (except cardiac sonography) & $73(84 \%)$ & $32(76 \%)$ & $20(83 \%)$ & $21(100 \%)$ & $9(100 \%)$ \\
\hline Bed side cardiac sonography & $82(94 \%)$ & $37(88 \%)$ & $24(100 \%)$ & $21(100 \%)$ & $9(100 \%)$ \\
\hline ECMO & $14(16 \%)$ & $4(10 \%)$ & $2(8 \%)^{\|}$ & $8(38 \%)^{\dagger}$ & $4(44 \%)$ \\
\hline Bed side surgery & $55(63 \%)$ & $22(42 \%)$ & $14(58 \%)$ & $19(90 \%)^{\dagger}$ & $9(100 \%)$ \\
\hline PDA surgery & $68(78 \%)$ & $26(62 \%)^{*}$ & $22(92 \%)$ & $20(95 \%)^{\dagger}$ & $9(100 \%)$ \\
\hline NEC surgery & $61(70 \%)$ & $26(62 \%)$ & $16(67 \%)$ & $19(90 \%)$ & $9(100 \%)$ \\
\hline NICU residents (No.) & $1.8 \pm 1.2(0-6)$ & $1.3 \pm 0.8^{*}$ & $2.0 \pm 1.1$ & $2.8 \pm 1.5^{\dagger}$ & $3.1 \pm 1.5$ \\
\hline Boardman in NICU (No.) & $1.9 \pm 1.3(1-7)$ & $1.6 \pm 0.9$ & $1.4 \pm 0.5^{\|}$ & $2.9 \pm 1.8^{\dagger}$ & $4.2 \pm 1.9^{\ddagger}$ \\
\hline Neonatology specialist (No.) & $1.3 \pm 0.9(0-4)$ & $0.9 \pm 0.6^{*}$ & $1.4 \pm 0.7^{\|}$ & $2.1 \pm 1.2^{\dagger}$ & $2.9 \pm 1.1^{\ddagger}$ \\
\hline NICU nurses (No.) & $17 \pm 12(4-66)$ & $11 \pm 5$ & $15 \pm 6^{\|}$ & $32 \pm 17^{\dagger}$ & $41 \pm 19^{\ddagger}$ \\
\hline Nurse specialist & $22(25 \%)$ & $7(17 \%)$ & $2(8 \%)^{\|}$ & $13(61 \%)^{\dagger}$ & $6(67 \%)$ \\
\hline Obstetrician (No.) & $5.9 \pm 4.4(-24)$ & $5.8 \pm 4.2$ & $5.7 \pm 5.5$ & $6.4 \pm 3.5$ & $6.8 \pm 2.7$ \\
\hline DR nurses (No.) & $8.9 \pm 5.7(1-41)$ & $7.9 \pm 4.5$ & $9.8 \pm 7.8$ & $10.1 \pm 4.9$ & $13.1 \pm 5.5^{\ddagger}$ \\
\hline DR ICS (No.) & $1.8 \pm 1.5(-8)$ & $1.2 \pm 0.8$ & $1.9 \pm 1.5$ & $2.7 \pm 2.0^{\dagger}$ & $3.6 \pm 2.5$ \\
\hline DR incubators (No.) & $0.8 \pm 0.9(-4)$ & $0.6 \pm 0.7$ & $1.0 \pm 0.8$ & $1.2 \pm 1.1^{\dagger}$ & $1.6 \pm 1.4$ \\
\hline GA<32 week delivery ratio (\%) & $5.6 \pm 5.4(-24.6)$ & $3.9 \pm 4.1$ & $7.1 \pm 5.2$ & $7.3 \pm 6.9$ & $7.0 \pm 7.8$ \\
\hline GA<28 week delivery ratio (\%) & $2.4 \pm 2.4(-10.3)$ & $1.6 \pm 1.7^{*}$ & $3.0 \pm 2.6$ & $3.2 \pm 2.9^{\dagger}$ & $3.3 \pm 3.4$ \\
\hline Preterm delivery No. per Obstetrician & $44.4 \pm 51.6(-265)$ & $32.8 \pm 52.7$ & $58.5 \pm 59.4$ & $51.3 \pm 33.6$ & $57.5 \pm 41.7$ \\
\hline GA $<32$ week delivery No. per Obstetrician & $7.1 \pm 8.4(-43.3)$ & $3.5 \pm 3.2^{*}$ & $9.7 \pm 8.4$ & $11.4 \pm 12.2^{\dagger}$ & $14.4 \pm 14.4$ \\
\hline
\end{tabular}

Abbreviations: NICU, neonatal intensive care unit; GA, gestational age; HFOV, high frequency oscillating ventilator; iNO, inhaled nitric oxide; TPN, total parental nutrition; ECMO, extracorporeal membrane oxygenation; PDA, patent ductus arteriosus; NEC, necrotizing enterocolitis; DR, delivery room; ICS, intensive care system.

Level 3 includes level $3+$.

${ }^{*} P$ value $<0.05$ when compared level 1 vs. 2 .

${ }^{\dagger} P$ value $<0.05$ when compared level 1 vs. 3 .

${ }^{\ddagger} P$ value $<0.05$ when compared level $3+$ vs. 3 except (3+ NICUs).

" $P$ value $<0.05$ when compared level 2 vs. 3 .

$P$ value by T-test. 
대 입원 수 증가가 두드러졌으며, 부산, 광주, 대전, 경상남도 지 역에서는 흡수율의 변화는 없었지만 늘어나는 미숙아 출생과 발 맞추어 절대 입원 수의 증가를 보였다(Table 2). 권역 별로 분류하 여 보았을 때 대전 - 충청도, 대구 - 경상북도, 전라북도, 광주 - 전 라남도는 아직 $100 \%$ 의 흡수율을 보이고 있지 못하여 지역환자 흡 수율의 지역별 편차가 여전히 존재한다(Table 3). 2009년과 2011년
의 단기간의 변화를 통해 지역거점병원의 지역화 역할에의 기여 를 논의하는 것이 한계가 있기는 하나, 강원도와 제주지역, 인천, 부산, 광주, 대전, 경상남도 지역은 지역화에 일부 기여한 것으로 사료된다.

2) 지역거점 신생아집중치료센터들의 활동성 비교

대상이 되는 13 개 센터에서 개소 전 - 후의 병상 수, 인력, 장비,

Table 2. The Number of Regional NICU Admission of Inborn Preterm Infants Born < 32 Gestational Week and the Absorption Rate of Regional Infants (2009 vs. 2011)

\begin{tabular}{|c|c|c|c|c|c|c|}
\hline \multirow{2}{*}{16 regions } & \multicolumn{3}{|c|}{ The year 2009} & \multicolumn{3}{|c|}{ The year 2011} \\
\hline & Inborn No. & Statistics & Absorption \% & Inborn No. & Statistics & Absorption \% \\
\hline Seoul & 1,095 & 582 & 188 & 1,114 & 571 & 195 \\
\hline Daegu & 194 & 143 & 136 & 184 & 166 & 111 \\
\hline Incheon & 95 & 203 & 47 & 145 & 227 & 64 \\
\hline Ulsan & 35 & 70 & 50 & 47 & 89 & 53 \\
\hline Gyeonggido & 441 & 812 & 54 & 468 & 882 & 53 \\
\hline Gangwondo & 88 & 97 & 91 & 108 & 99 & 109 \\
\hline Chungcheongbukdo & 55 & 96 & 57 & 49 & 104 & 47 \\
\hline Gyeongsangbukdo & 6 & 177 & 3 & 53 & 189 & 28 \\
\hline Gyeongsangnamdo & 113 & 191 & 59 & 164 & 268 & 61 \\
\hline Jejudo & 21 & 36 & 58 & 35 & 32 & 109 \\
\hline Total & 2,858 & 3,075 & 93 & 3,264 & 3,481 & 94 \\
\hline
\end{tabular}

Abbreviation: NICU, neonatal intensive care unit.

Absorption \% = regional inborn No. $/$ regional statistics No. * $100 \%$.

Table 3. The Number of Integrated Regional NICU Admission of Inborn Preterm Infants Born < 32 Gestational Week and the Absorption Rate of Integrated Regional Infants (2009 vs. 2011)

\begin{tabular}{|c|c|c|c|c|c|c|}
\hline \multirow{2}{*}{8 Integrated regions } & \multicolumn{3}{|c|}{ The year 2009} & \multicolumn{3}{|c|}{ The year 2011} \\
\hline & Inborn No. & Statistics & Absorption \% & Inborn No. & Statistics & Absorption \% \\
\hline Seoul.Incheon. Gyeonggido & 1,631 & 1,597 & 102 & 1,727 & 1,680 & 103 \\
\hline Gangwondo & 88 & 97 & 91 & 108 & 99 & 109 \\
\hline Daejeon. Chungcheongdo & 237 & 310 & 76 & 294 & 399 & 74 \\
\hline Daegu.Gyeongsangbukdo & 200 & 320 & 63 & 237 & 355 & 67 \\
\hline Busan.Ulsan. Gyeongsangnamdo & 450 & 437 & 103 & 617 & 599 & 103 \\
\hline Jollabukdo & 85 & 106 & 80 & 88 & 110 & 80 \\
\hline Gangju. Jollanamdo & 146 & 172 & 85 & 158 & 207 & 76 \\
\hline Jejudo & 21 & 36 & 58 & 35 & 32 & 109 \\
\hline Total & 2,858 & 3075 , & 93 & 3,264 & 3,481 & 94 \\
\hline
\end{tabular}

Abbreviation: NICU, neonatal intensive care unit.

Absorption \% = regional inborn No. / regional statistics No. * $100 \%$. 
산과, 협진과 상황의 변화를 조사하였다. 활동성 비교 시기는 개 소 전 1년과 개소 후 최소 6 개월까지 (2009년 개소, 개소 후 3 년 조 사; 2010년 개소, 개소 후 2년 조사; 2011년 개소, 개소 후 1년 조사; 2012년 개소, 개소 후 최소 6개월 조사) 신생아중환자실에 입원한 환자 수, 주요 질환 건수, 수술건수, 분만한 산모 수 등을 조사하였 다.

지역거점 신생아집중치료센터 개소 후 정부 지원의 일괄적인 10 병상 확보와 자조적인 병상 확장이 추가되어 평균 11병상(10-21 병상)이 더 확보되어, 개소 후 평균 26병상(16-36병상)의 센터가 되어 가시적인 병상과 면적의 확장을 확인할 수 있었다. 신생아집 중치료센터의 장비 수 증가가 이루어졌으나 소량의 혈액채취검 사가 가능하지 않은 1 개소, 흡입용 일산화질소 가스가 가능하지 않은 3 개소, 저체온치료 장비가 구비되지 않은 5 개소가 존재하였 다. 근무 전문의 수와 세부 전문의 수가 늘어났으나, 근무 전문의 가 1 명인 곳이 3 개소에 남아있었고, 간호 인력이 전반적으로 증가 하면서 전공의 수가 부족한 곳에서 전문 간호사의 활용도를 높여 운영하기도 하였다. 동맥관 개존증 수술, 괴사성 장염 수술, 뇌실 내 배액시술, 미숙아 망막증 레이져 시술이 대부분의 센터에서 가 능하였으나 1 개소에서만 동맥관 개존증 수술이 불가능하였다. 한 센터에서만 산과 전문의 수와 분만장 간호 인력이 보충되었고, 다 른 곳에서는 산과와 분만장 상황에 변화는 없었다.

개소 전 · 후의 활동성을 비교하였을 때, 개소 후 모든 센터에서 출생 재태주수 32 주 미만의 미숙아 입원 수가 증가하였다. 호흡곤 란증후군 진단 환자 수 또한 모든 센터에서 개소 후 증가된 양상을 보여 중증 환자의 수가 증가함을 알 수 있다. 대부분의 병원에서 산과 인력의 차이는 없었으나 D, E, J, L병원에서는 개소 첫 1 년째 분만 수 증가를 보였고, 분만가능 산과 전문의 수가 9 명으로 많았
던 M병원은 분만 수의 급격한 증가를 보였다. 미숙아 분만율은 C, $\mathrm{E}$ 병원을 제외하고 모든 센터에서 증가하였다. 신생아중환자실 환 자의 수술 건 수는 $\mathrm{E}, \mathrm{H}, \mathrm{I}$ 병원을 제외하고 다른 센터들에서는 개 소 후 증가된 양상을 보였다. C, D, H 세 곳의 병원에서는 다른 병 원으로의 환자 이송 건수가 증가되었고 이는 입원 수가 늘어나면 서 수술을 요하는 중증의 환자가 늘어났지만 협진과 전담의의 부 족으로 수술을 위해 다른 병원으로 이송한 것으로 나타났다.

3) 활동성 증가가 두드러진 센터의 요인(활동성 증가 병원 vs. 그 외의 병원)

정부지원 지역거점 신생아집중치료센터 13 곳 중 활동성이 높은 병원은, 개소 1 년 전과 비교 시 개소 후에도 높은 병상 당 연간 32 주 미만 입원 수를 유지한 곳으로 정의하였다. 참고사항으로 2011 년 1년간 국내 신생아중환자실 전수 조사에서 병상 당 32 주 미만 입원 수의 상위 10 percentile ( 90 백분위수)는 4.7 명으로 지역거점 센터 중에서 병상당 연간 32 주 미만 입원 수가 5 명 이상으로 계산 된 센터들을 활동성이 증가가 두드러진 병원으로 분류하였다. 여 기에 해당되는 병원은 $\mathrm{A}, \mathrm{D}, \mathrm{M}$ 병원으로 다른 병원들과 비교 시 개 소 후 첫 1 년간 재태주수 32 주 미만의 입원 수가 유의하게 많았다 (개소 1년 전 $64 \pm 17$ 명 vs. $42 \pm 19$ 명 $\rightarrow$ 개소 1 년 후 $124 \pm 6$ 명 vs. 60 \pm 22 명, $P=0.028$ by Mann-Whitney test). 개소 후 첫 1년간 28 주 미만의 극소재태주수의 미숙아 입원 수도 유의하게 많았으며(개 소 1 년 전 $18 \pm 4$ 명 vs. $12 \pm 9$ 명 $\rightarrow$ 개소 1 년 후 $42 \pm 13$ 명 vs. $20 \pm 9$ 명, $P=0.07)$, 개소 후 첫 1 년 동안 호흡곤란증후군으로 진단받고 입원치료 받은 환자 수 또한 통계적으로 유의하게 많았다(개소 1 년 전 $129 \pm 64$ 명 vs. $41 \pm 23$ 명 $\rightarrow$ 개소 1 년 후 $189 \pm 50$ 명 vs. $62 \pm 30$ 명, $P=0.028)$. 활동성이 높은 $\mathrm{A}, \mathrm{D}, \mathrm{M}$ 병원은 다른 병원들에 비해 개소 후 첫 1년 동안 타과 협조가 필요한 수술 건수가 많았으나, 통

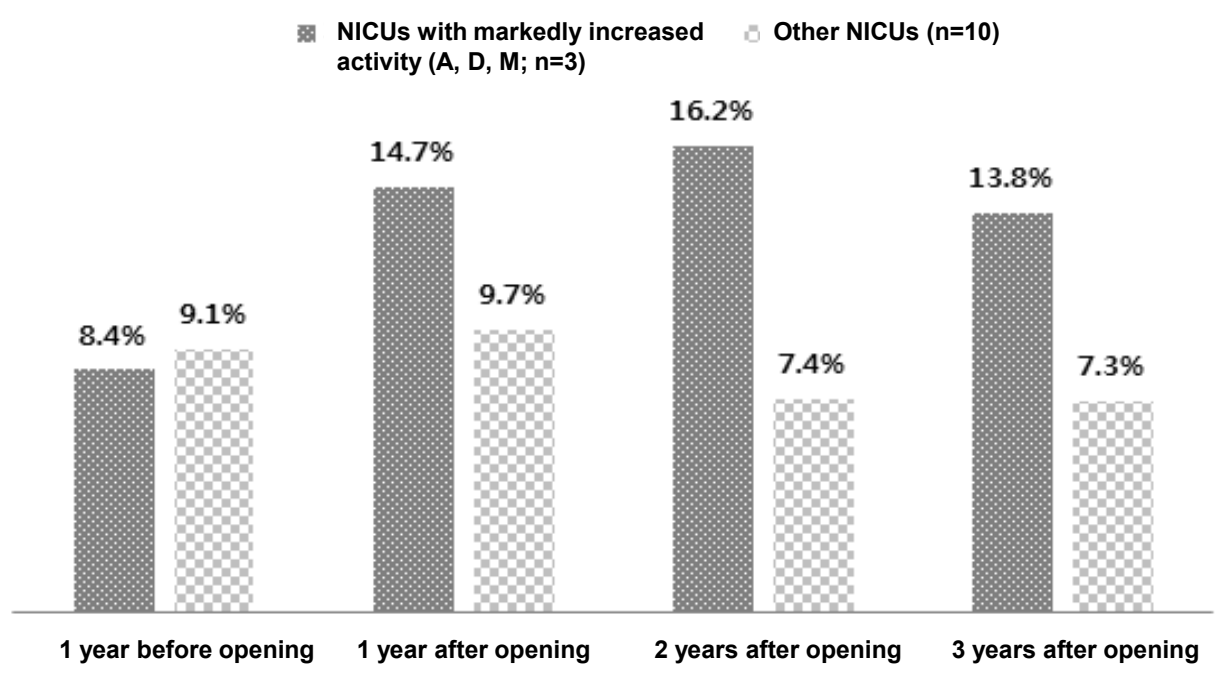

Fig. 1. The comparison of annual delivery rate below 32 gestational week, among regional hub NICUs with different activity. 
계적으로 유의하지는 않았다(개소 1 년 전 $34 \pm 15$ 건 vs. $17 \pm 12$ 건 $\rightarrow$ 개소 1 년 후 $61 \pm 11$ 건 vs. $24 \pm 14$ 건, $P=0.161)$.

활동성의 증가가 두드러진 $\mathrm{A}, \mathrm{D}, \mathrm{M}$ 병원을 그 외의 병원과 개소 후 병상 수, 장비, 인력, 분만 활동 등을 비교하여 보았다(Table 4). 신생아중환자실 크기와 장비의 차이는 미미하였으나 인력 보강 부분에서 두드러진 차이를 보여 전공의, 전문의 수와 함께 간호사 및 전문 간호사의 수가 높은 경향을 보였다. 산과 인력 및 시설 변

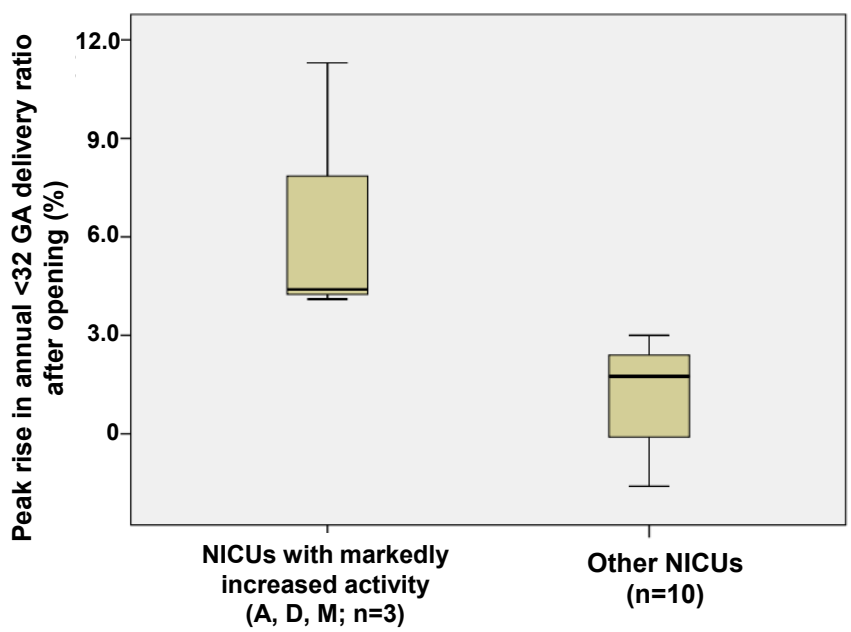

Fig. 2. The comparison of peak rise in annual delivery rate below 32 gestational week, among regional hub NICUs with different activity ( ${ }^{*} P=0.007$ by Mann-Whitney test).
화는 미미하였으나, 활동성이 높은 $\mathrm{A}, \mathrm{D}, \mathrm{M}$ 병원은 그 외의 병원들 과 비교 시 산과의 미숙아 분만 활동 증가가 두드러졌다(Fig. 1, 2). 특히 산과 전문의가 유일하게 2 명 늘어난 $\mathrm{D}$ 병원의 미숙아 분만율 이 독보적으로 증가되었다(32주 미숙아 분만율: 개소 1 년 전 $9.9 \%$ $\rightarrow$ 개소 1 년 후 $21.2 \%$ ).

4) 지역거점 신생아집중치료센터 기능 평가 결론

지역거점 신생아집중치료센터들의 개소로 국내 신생아중환자 실의 지역화에 기여하는 부분이 있으며, 센터 각각의 활동성을 조 사해보았을 때, 모든 센터에서 출생 재태주수 32 주 미만의 미숙아 입원이 개소 후 증가되고 이와 관련된 질환 군, 수술 건 수 등이 증 가되는 양상을 보였다. 그 중에서도 독보적인 활동성의 증가를 보 였던 $\mathrm{A}, \mathrm{D}, \mathrm{M}$ 세 곳의 병원에서는 그 외의 병원과 비교 시 신생아 중환자실의 크기와 장비의 차이는 없었지만, 소아청소년과 전공 의, 전문의, 간호사, 전문간호사 수가 높은 경향을 보이고 산과 인 력이 보충된 병원에서 미숙아 분만율이 증가된 양상을 보여, 인력 부분의 보충이 활동성에 중요한 영향을 주었다고 평가할 수 있다.

\section{3. 정부 지원 사업에의 제언}

1) 병상 수 확보 및 활동성을 올리는 지원이 필요

2011년 1년간 고위험 신생아의 출생 수로 계산한 국내 신생아중 환자실 필요 병상 수는 1,730 병상으로 현재 병상에서 400 병상 이 상이 필요하며, 2011년 통계청 출생아로 계산한 국내 신생아중환 자실의 부족 병상 수는 200-600병상으로 추정된다 ${ }^{3-5,16)}$. 정부 지

Table 4. The Comparison among Regional Hub NICUs with Different Activity

\begin{tabular}{|c|c|c|c|}
\hline Factors after regional hub opening & NICUs with markedly increased activity (A, D, M; n=3) & Other NICUs $(n=10)$ & $P$ value \\
\hline NICU beds (No.) & $23 \pm 5$ & $27 \pm 6$ & 0.371 \\
\hline Beds increment (No.) & $11 \pm 1$ & $11 \pm 3$ & 0.217 \\
\hline HFOV (No.) & $5 \pm 2$ & $5 \pm 3$ & 0.692 \\
\hline Incubator (No.) & $29 \pm 4$ & $28 \pm 8$ & 0.692 \\
\hline Patient monitor (No.) & $39 \pm 22$ & $29 \pm 11$ & 0.573 \\
\hline Infusion pump (No.) & $91 \pm 27$ & $68 \pm 16$ & 0.161 \\
\hline O2 outlet (No.) & $67 \pm 32$ & $55 \pm 17$ & 0.573 \\
\hline NICU residents (No.) & $3.7 \pm 0.6$ & $2.2 \pm 1.1$ & 0.049 \\
\hline NICU nurses (No.) & $32.7 \pm 13.9$ & $24.8 \pm 9.8$ & 0.371 \\
\hline Nurse specialist & $2(67 \%)$ & $4(40 \%)$ & 0.573 \\
\hline
\end{tabular}

Abbreviations: NICU, neonatal intensive care unit; HFOV, high frequency oscillating ventilator; ICS, intensive care system.

$P$ value by Mann-Whitney test. 
Table 5. Integrated Regional Distribution of Regional Hub NICUs according to the Suggested Levels of NICU

\begin{tabular}{lccc}
\hline 8 Integrated regions & Integrated regional hub NICU & Upper level regional hub NICU & Lower level regional hub NICU \\
\hline Seoul. Incheon. Gyeonggido & $5^{*}$ & $6^{* *^{\dagger}}$ & $7^{\dagger}$ \\
Gangwondo & 0 & $1^{*}$ & 1 \\
Daejeon. Chungcheongdo & 0 & $4^{* *}{ }^{\dagger}$ & 0 \\
Daegu. Gyeongsangbukdo & 0 & 0 & $2^{*}$ \\
Busan.Ulsan.Gyeongsangnamdo & 0 & $2^{* \dagger}$ & $4^{*}$ \\
Jollabukdo & 0 & 0 & $1^{*}$ \\
Gangju. Jollanamdo & 0 & $1^{*}$ & $1^{\dagger}$ \\
Jejudo & 0 & 0 & $1^{*}$ \\
Total & 5 & 14 & 17 \\
\end{tabular}

*Regional hub NICUs assigned till 2011.

${ }^{\dagger}$ Regional hub NICUs assigned at 2012 (these NICUs are included assuming that 10 more beds would be obtained).

원으로 국내의 신생아중환자실 병상 수가 소폭 증가하고는 있으 나 급격히 늘어나는 고위험 미숙아의 수에는 부족하고, 현실적으 로 신생아중환자실 요건을 갖추는데 어려움이 있는 병원들에서 중환자실보다 여건이 열악한 일반 병실에서 신생아중환자를 치 료하고 있을 가능성이 있다. 따라서, 국내의 신생아중환자실 병상 수를 확보하는 것이 우선되어야 한다.

같은 병상 수에서도 신생아중환자실 기능을 올릴 수 있는 방편 으로 활동성을 올리기 위한 지원이 필요하다. 국내 신생아중환자 실 활동성을 평가하였을 때, 병상 수 외에도 인공호흡기와 같은 장비 보충, 전공의 수, 전문의 수, 세부전문의 수, 간호 인력 등 인 력 보충이 필요하며, 산과 전문의 및 시설 보충을 통해 산과의 미 숙아 분만 여력을 올리는 일이 필요하다. 부족한 요소에 대한 기 준은 활동성 지표에 따른 병원 등급별 요소들을 활용하여 기준을 제시할수 있다.

2) 등급별 신생아중환자실 분포 및 권역 별 유출 환자에 따른 정 부지원의 다각화 필요

앞서 국내 신생아중환자실의 기능 평가 시 활동성을 기준으로 등급화 한 결과, 등급별로 병상 수의 규모가 달라진다. Level 2 의 평균 병상 수는 15 병상으로 15 병상 이상의 규모의 신생아중환자 실을 일반지역거점병원, level 3 의 평균 병상 수인 25 병상 이상 규 모의 병원을 상급지역거점병원, level $3+$ 를 권역거점병원으로 명 칭하고 35 병상 이상 규모의 병원으로 등급화하여 국내 신생아중 환자실의 분포를 보면 지역화를 위한 지원 계획에 참고할 수 있을 것이다 (Table 5). 상급지역거점병원이 없는 곳은 대구, 경상북도 와 전라북도, 제주 권역으로 일반지역거점병원의 등급상승이 필 요하다. 대전 · 충청도 권역에는 일반지역거점병원이 없고, 광주, 전라도 권역은 일반지역거점병원에 해당되는 병원이 1 개 존재한 다. 효율적인 거점병원 지원을 위해 현재 권역 별 흡수율과 유출 환자 수를 고려하여, 통계청 대비 권역 내 신생아중환자실 흡수율 이 $100 \%$ 가 되지 않는 지역을 중심으로 정부 지원을 계획하는 것이
필요하다.

\section{결론}

국내의 현실상 병상 수나 입원 수와 같은 양적인 지표 사용을 통 해 신생아중환자실의 기능 현황을 파악할 수 있으며 본 종설에서 제시한 활동성 지표를 이용하여 신생아중환자실의 기능 평가에 사용할 수 있다. 향후 신생아중환자실의 기능 파악의 도구로 본 종설에서 제시한 양적인 활동성 지표 외에 생존율을 통한 질적인 지표 사용이 마련되어야 한다. 미숙아 생존율을 지표로 사용하기 위해서는 국가 규모의 네트워크 형성을 통해 신생아중환자실에 입원하는 환자들이 등록되어 이송 시 추적자료 확인이 가능해야 할 것이며, 연간 생존율을 넘어 장기적인 생존율 변화 평가를 통 해 질적인 지표 사용의 계획이 마련되어야 할 것이다. 이러한 기 능평가 지표들을 활용하여 신생아중환자실 기능 파악을 통해 지 역화에 도움이 되는 효율적인 정부지원이 요구된다.

\section{감사의 글}

본 연구는 보건복지부 연구용역의 과제로 수행되었으며, 과제 의 자료 수집에 김애란(서울아산병원), 김영돈(제주대학교병원), 김천수(계명대학교 동산병원), 송은송(전남대학교병원), 신승한 (서울대학교병원), 심소연(길병원), 이주영(서울대학교병원), 임 진아(충북대학교병원), 정지미(부산백병원), 최병민(고려대학교 안산병원), 최창원(분당서울대학교병원) 선생님들께서 연구원으 로서 주도적인 역할을 해주셨습니다. 자료 수집에 협조해 주신 전 국의 87개 신생아중환자실 담당 선생님들께도 감사를 표하며, 협 조해 주신 병원은(가나다순), 가톨릭대학교 부천성모병원, 서울 
성모병원, 성빈센트병원, 여의도성모병원, 의정부성모병원, 인천 성모병원, 강동경희대학교병원, 강릉아산병원, 강북삼성병원, 강 원대학교병원, 건국대학교병원, 건양대학교병원, 경북대학교병 원, 경상대학교병원, 경희대학교병원, 계명대학교 동산병원, 고 려대학교 구로병원, 고려대학교병원, 고려대학교 안산병원, 고신 대학교 복음병원, 광명성애병원, 광주기독병원, 길병원, 단국대 학교병원, 대구가톨릭대학교병원, 대구파티마병원, 동국대학교 일산병원, 동아대학교병원, 명지병원, 미즈메디병원, 보라매병 원, 부산대학교병원, 부산성모병원, 분당서울대학교병원, 삼성서 울병원, 삼성창원병원, 서울대학교병원, 서울아산병원, 서울여성 병원(인천), 서울여성병원(부천), 성애병원, 세종병원, 순천향대 학교 구미, 부천, 서울, 천안병원, 아주대학교병원, 안동병원, 양 산부산대학교병원, 원주기독병원, 강남세브란스병원, 연세대학 교 세브란스병원, 영남대학교병원, 울산대학교병원, 원광대학교 병원, 노원을지병원, 을지대학병원, 이화여자대학교 목동병원, 인제대학교 상계백병원, 서울백병원, 부산백병원, 일산백병원, 해운대백병원, 인하대학교병원, 일산병원, 일신기독병원, 전남대 학교병원, 전북대학교병원, 전주예수병원, 제일병원, 제주대학교 병원, 제주한라병원, 조선대학교병원, 좋은문화병원, 중앙대학교 병원, 차의과학대학교 강남차병원, 구미차병원, 분당차병원, 충 남대학교병원, 충북대학교병원, 한림대학교 강남성심병원, 강동 성심병원, 성심병원, 한양대학교 구리병원, 한양대학교병원, 한 일병원, 현대병원입니다. 마지막으로 연구보조원으로 자료 정리 에 도움을 준 박재영 학생(이화여자대학교 의학전문대학원)의 노 고에 감사합니다.

\section{REFERENCES}

1) Korean Statistical Information Service. Birth statistics. [cited 2012 Oct. 26] Available from: URL:http://www.kosis.kr/ abroad/abroad_01List.jsp?parentID=A.

2) Han YJ, Seo K, Shin SM, Lee SW, Do SR, Chang SW. Low birth weight outcomes and policy issues in Korea. Seoul: Korea Institute for Health and Social Affairs. 1999. Report No.: 199910.

3) Shin S, Park J, Namgung R, Park M, Son D, Lee J. Establishment of an effective healthcare system for high risk newborn infants. Seoul: Korea Health Promotion Foundation, Management Center for Health Promotion. 2005. Report No.:2005-65.

4) Chang YS; The Committee on Statistics of the Korean Society of Neonatology. The survey on the actual conditions of neonatal intensive care units and analysis of survival rate of high-risk newborn infants. Seoul: Korea Health Promotion Foundation, Management Center for Health Promotion. 2010.
Report No.: 2010-11.

5) Kim HS, Kim EA, Choi BM, Choi CW, Shim SY, Jung JM, et al. Evaluation of performance and efficiency in operation of neonatal intensive care unit. Available from: URL: http:// www.prism.go.kr/homepage/search/retrieveIntegrate Search.do. In press 2013.

6) Phibbs CS, Baker LC, Caughey AB, Danielsen B, Schmitt SK, Phibbs RH. Level and volume of neonatal intensive care and mortality in very-low-birth-weight infants. N Engl J Med 2007;356:2165-75.

7) Tucker J; UK Neonatal Staffing Study Group. Patient volume, staffing, and workload in relation to risk-adjusted outcomes in a random stratified sample of UK neonatal intensive care units: a prospective evaluation. Lancet 2002;359:99-107.

8) Robertson PA, Sniderman SH, Laros RK Jr, Cowan R, Heilbron D, Goldenberg RL, et al. Neonatal morbidity according to gestational age and birth weight from five tertiary care centers in the United States, 1983 through 1986. Am J Obstet Gynecol 1992;166:1629-41; discussion 1641-5.

9) Lorch SA, Baiocchi M, Ahlberq CE, Small DS. The differential impact of delivery hospital on the outcomes of premature infants. Pediatrics 2012;130:270-8.

10) Hajj H, Dagle JM. Genetics of patent ductus arteriosus susceptibility and treatment. Semin Perinatol 2012;36:98-104.

11) Yoon BH, Romero R, Kim KS, Park JS, Ki SH, Kim BI, et al. A systemic fetal inflammatory response and the development of bronchopulmonary dysplasia. Am J Obstet Gynecol 1999;181: 773-9.

12) Kuban K, Sanocka U, Leviton A, Allred EN, Pagano M, Dammann O, et al. White matter disorders of prematurity: association with intraventricular hemorrhage and ventriculomegaly. The Developmental Epidemiology Network. J Pediatr 1999;134:539-46.

13) St Clair C, Norwitz ER, Woensdregt K, Cackovic M, Shaw JA, Malkus $\mathrm{H}$, et al. The probability of neonatal respiratory distress syndrome as a function of gestational age and lecithin/sphingomyelin ratio. Am J Perinatol 2008;25:473-80.

14) Gordon PV, Swanson JR, Attridge JT, Clark R. Emerging trends in acquired neonatal intestinal disease: is it time to abandon Bell's criteria? J Perinatol 2007;27: 661-71.

15) Tapia JL, Agost D, Alegria A, Standen J, Escobar M, Grnadi C,et al. Bronchopulmonary dysplasia: incidence, risk factors and resource utilization in a population of South American very low birth weight infants. J Pediatr (Rio J) 2006;82:15-20.

16) Choi JS, Bae CW, Chang YS, Lee NH, Hong WR. Policy issues on neonatal intensive care for low birth weight infants. Seoul: Korea Institute for Health and Social Affairs. 2012. Report No.: 2012-47-9. 


\section{신생아집중치료센터의 기능평가 및 효율적인 운영 방안}

\section{차의과학대학교 강남차병원 소아청소년과학교실, 서울대학교 의과대학 소아청소년과학교실*}

김은선 · 신승한* · 김한석*

미숙아 환자 수의 증가와 함께 신생아중환자실의 기능이 중요시되고 있는 요즈음 2012 년 3월까지 전국에서 총 13 개소 에서 정부지원 지역거점 신생아집중센터가 개소되었다. 단순한 병상 수의 증가 뿐만 아니라 신생아중환자실이 얼마나 기능하고 있는지 평가하고 효율적인 지원을 하는 것이 필요하다. 이를 위해 신생아중환자실 기능 평가를 위한 도구로 2011년도의 연간 출생 재태주수 32 주 미만의 입원 환자수를 활동성의 지표로 삼아 국내 신생아중환자실의 기능을 등급 화하여 분석하였다. 병상 수의 규모가 클수록 활동성이 증가되나, 병상 수 외에도 장비, 신생아중환자실 인력, 산과 인 력 등의 요인이 독립적으로 활동성에 영향을 주었다. 활동성 지표로 등급화 된 병상 규모별로 시설·장비 ·인력의 기준 을 제시할 수 있으며 역으로 기준에 맞쵰을 때 활동성을 예측하여 신생아중환자실 기능의 평가 도구로 사용할 수 있을 것이다. 한편, 개소 후 최소 6 개월 이상의 자료를 확보할 수 있었던 지역거점 신생아집중치료센터 13 곳의 개소 전·후 를 비교한 결과 모든 센터에서 활동성 지표가 증가되었고 지역화에 일부 기여하였다. 개소 후 두드러지게 활동성 지표 가 증가되었던 3 곳의 센터는 그 외의 센터와 비교 시 크기와 장비의 차이는 없었으나 전공의 · 전문의 · 간호사 · 전문간 호사를 포함한 신생아중환자실 인력과 산과 인력의 보충에 차이를 보였다. 정부의 거점병원 지원에 있어서 지역간 등 급별 신생아중환자실 분포 현황 및 권역 별 유출 환자 수에 따라 다각적인 전략이 필요하다. 